\title{
Histologic Analysis of Ridge Preservation Using Deproteinized Porcine Bone: A Retrospective Human Study
}

\author{
Eun-Sik Park, DDS', Jeong-Cheol Park, DDS², Seong-Ho Choi, DDS, PhD³ , Dong-Woon Lee, \\ $\mathrm{DDS}, \mathrm{PhD}^{4 *}$ \\ ${ }^{1}$ Resident, Department of Periodontology, Veterans Health Service Medical Center, Seoul, Korea \\ 2Director, Private Practice, Hyo dental Clinic, Seoul, Korea \\ ${ }^{3}$ Professor, Department of Periodontology, College of Dentistry, Yonsei University, Seoul, Korea \\ ${ }^{4}$ Chair, Department of Periodontology, Veterans Health Service Medical Center, Seoul, Korea \\ *Corresponding author: Dong-Woon Lee, Department of Periodontology, Veterans Health Service Medical \\ Center, 53 Jinhwangdo-ro 61-gil, Gangdong-gu, Seoul 05368, Korea. \\ Tel: +82-2-2225-1899. Fax: +82-2-2225-1659. E-mail: dongden@daum.net
}

\section{OPEN ACCESS}

pISSN 1229-5418

eISSN 2671-6623

Implantology 2021; 25(1): 1-9

https://doi.org/10.32542/implantology.2021001

Received: October 22, 2020

Revised: January 3, 2021

Accepted: January 5, 2021

ORCID

Eun-Sik Park

https://orcid.org/0000-0003-3361-2620

Seong-Ho Choi

https://orcid.org/0000-0001-6704-6124

Dong-Woon Lee

https://orcid.org/0000-0002-0796-9100

Copyright $(\odot) 2021$. The Korean Academy of Oral \& Maxillofacial Implantology

\footnotetext{
This is an Open Access article distributed under the terms of the Creative Commons Attribution Non-Commercial License (http://creativecommons. org/licenses/by-nc/4.0/) which permits unrestricted non-commercial use, distribution, and reproduction in any medium, provided the original work is properly cited.
}

\section{Abstract}

Purpose: In this retrospective study a histomorphometric analysis was conducted of sites where alveolar ridge preservation was performed using deproteinized porcine bone mineral.

Materials and Methods: Twenty-five patients who underwent ridge preservation after extraction were selected in this study. Histomorphometric analysis was performed according to the healing period (24 weeks) and socket location. The proportions of new bone, residual bone graft material, and fibrovascular tissue were calculated. The demographic characteristics of the two groups were compared using the t-test for continuous variables.

Results: The healing duration groups showed no significant differences between the proportions of new bone $(p=.692)$, residual graft $(p=.875)$, and fibrovascular tissue $(p=.619)$. The non-molar and molar area groups showed no significant differences between the proportions of new bone $(p=999)$, residual graft $(p=.638)$, and fibrovascular tissue $(p=.723)$. The maxilla and mandible groups showed no significant differences between the proportions of new bone $(p=.185)$, residual graft $(p=.736$ ), and fibrovascular tissue $(p=.125)$.

Conclusion: No significant differences were observed between the results of the histomorphometric analysis of the two groups based on the healing duration and location.

Keywords: Alveolar ridge augmentation, Bone regeneration, Histology

\section{Introduction}

The alveolar ridge is a tooth-dependent structure. The development of the alveolar bone begins with the eruption of teeth, and the loss of a tooth is followed by resorption and atrophy of the alveolar bone. ${ }^{1,2}$ Therefore, the alveolar bone begins to shrink after extraction, and horizontal and vertical bone resorption occurs. ${ }^{3}$ The volume of the alveolar bone 
reduces by $26 \%$ after a year, and the width decreases by $40-60 \%$ after 3 years. ${ }^{2,4}$ The more damaged the bony wall, the more extensive is the amount and pattern of alveolar bone loss. Fibrous tissue fills the socket, and the process of normal bone remodeling and osteogenesis are disturbed. ${ }^{5}$ Morphological changes, such as a higher tendency for bone resorption on the buccal side than on the lingual side, can affect successful placement and osseointegration of implants. We can reduce the demand for additional bone graft surgery, prevent bone resorption, and predict the improvement in the esthetics of the tissue around the implant and long-term success of implants by ridge preservation procedures. ${ }^{6,7}$

Applying bone graft material to the socket is recommended to maintain the volume of the extraction area. $^{8-10}$ Autogenous bone grafting can be considered; however, it can create complications within the donor area. Therefore, several researchers are proceeding to develop adequate alloplastic bone. ${ }^{11}$ Currently, several bone grafting materials that can be used in ridge preservation have been developed and widely used in the market. This resolves the limitations of autogenous grafts.

Several studies on alveolar ridge preservation have focused on volumetric changes and the histological properties of the alveolar ridge based on different materials and surgical techniques. However, relatively few experiments have focused on histological analysis of the deproteinized porcine bone mineral (DPBM). In this retrospective study, histomorphometric analysis of new bone formation, residual bone graft material, and fibrovascular tissue after ridge preservation using DPBM was conducted. A histomorphometric analysis was performed of 25 areas where the alveolar ridge was preserved using DPBM by stratifying them by the healing period and socket location.

\section{II . Materials and Methods}

Using patient charts, a histomorphometric analysis was performed of the sites where ridge preservation was performed using DPBM and factors affecting its results were evaluated. The Institutional Review Board of Veterans Health Service Medical Center reviewed and approved the protocol for this retrospective study (BOHUN 2016-08-023).

Twenty-five patients (16 men and nine women) who underwent ridge preservation after extraction of a single tooth between January 2015 and December 2016 and those who needed extraction from the Department of Periodontology of Veterans Health Service Medical Center were included in this study. The mean patient age was $60.96 \pm 10.83$ years (range, $37-80$ years). The distribution according to the socket locations was as follows: maxillary premolars $(n=5)$, maxillary molars $(n=4)$, mandibular premolars $(\mathrm{n}=3)$, and mandibular molars $(\mathrm{n}=13)$ (Table 1). 
On the day of extraction, ridge preservation was performed using DPBM (THE Graft, Purgo, Seoul, South Korea) and a collagen membrane (Bio-Gide, Geistlich Pharma AG, Switzerland or Ossix Plus, Datum, Israel). To achieve primary closure, the buccal flap was released. Interrupted sutures were placed with nylon (5-0 blue nylon, AILEE, South Korea). On completion of the healing period, a $2.7-\mathrm{mm}$ inner diameter trephine bur (Trephine Bur Kit Xit, Dentium, South Korea) was used to harvest the bone on implant placement sites, which were placed with planning of prosthetic treatment. These bone cores were fixed using 10\% formalin, decalcified using 5\% formic acid, and embedded in paraffin. Serial

Table 1. Demographic characteristics of the selected patients

\begin{tabular}{cc}
\hline Patients $(\mathrm{n}=25)$ & Demographic results \\
\hline Age (years) & \\
Mean age (SD) & $61.28 \pm 10.88$ \\
Range & $37-80$ \\
Sex & $16 / 9$ \\
Male/Female & \\
Sites & $9(6 / 3)$ \\
Non-molar (Maxilla/Mandible) & $16(4 / 12)$ \\
\hline Molar (Maxilla/Mandible) &
\end{tabular}
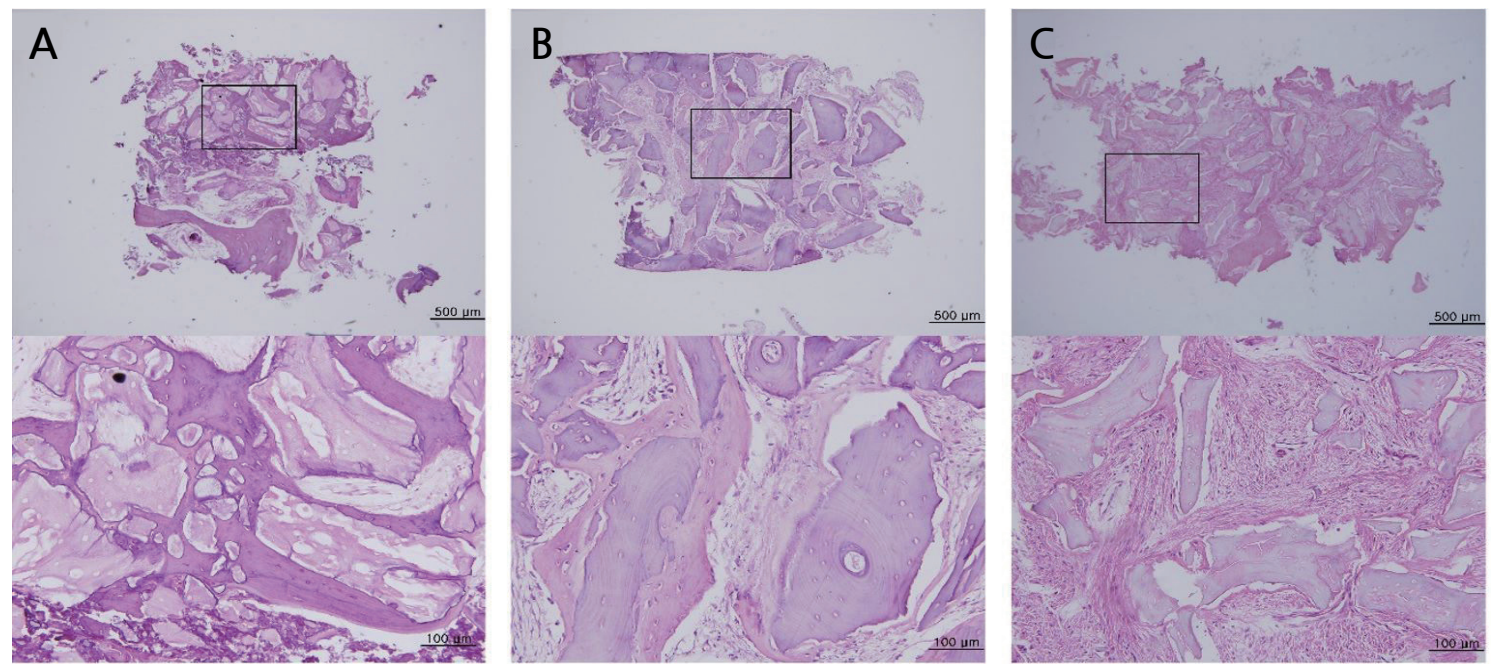

Fig. 1. Representative histologic specimens according to healing patterns. Images of hematoxylin and eosin (H\&E) stained tissue represent the entire specimen (magnification 40x) and a high magnification view (magnification 200x) of the boxed area in each panel. (A) A specimen with 32 weeks healing in the mandibular molar area. The formation of the new bone around the residual bone grafting material is observed and it shows a good healing pattern. (B) A specimen with 26 weeks healing in the mandibular molar area. New bone formation is observed around some residual bone grafts. (C) A specimen with 18 weeks healing in the mandibular molar area. Residual bone grafting material is surrounded by fibrovascular tissue and no formation of new bone is observed. 
perpendicular sections (5- $\mu \mathrm{m}$ thickness) were cut along the center of each specimen, and the central sections were stained with hematoxylin and eosin (Fig. 1). The area and proportion of new bone, residual bone graft material, and fibrovascular tissue were calculated using imaging software (Image-Pro Plus 7, Media Cybernetics Inc., USA) and histologic slides of biopsy samples for the histomorphometric analysis as follows:

\section{Analysis according to healing time}

The group was divided into those with healing durations of 24 weeks or less and those with healing durations of more than 24 weeks.

\section{Analysis according to socket location}

(a) Subdivision 1: The group was subdivided into non-molar area and molar area groups.

(b) Subdivision 2: The group was subdivided into maxilla and mandible groups.

All data are presented as the mean \pm standard deviation (SD) or frequency with percentage. The demographic characteristics of the two groups were compared using the $t$-test for continuous variables. Statistical significance was set at $p<.05$. All the analyses were conducted using R 4.0.1 (R Development Core Team; R Foundation for Statistical Computing, Austria).

\section{III . Results}

Histological analysis was conducted. The histologic specimens showed diverse bone maturities and formation without an inflammatory response or fibrous encapsulation. In addition, the osteoid tissue, woven bone, and osteoblasts were observed adjacent to the mature bone.

\section{Healing time (24 weeks)}

The proportions ( \pm SDs) of new bone, residual graft, and fibrovascular tissue were $9.53 \pm 12.94 \%$, $13.84 \pm 8.81 \%$, and $76.62 \pm 11.60 \%$ in the group with healing durations of less than 24 weeks and 11.44 $\pm 7.74 \%, 14.44 \pm 9.30 \%$, and $74.12 \pm 12.50 \%$ in group with a healing period of 24 weeks or more, respectively. There was no significant difference between the proportions of new bone $(p=.692)$, residual graft $(p=.875)$, and fibrovascular tissue $(p=.619)$ of the two groups. 
Table 2. Characteristics according to healing period and socket location

\begin{tabular}{|c|c|c|c|c|c|c|c|c|c|}
\hline & $\begin{array}{c}\text { Healing } \\
\text { period }<24 \\
\text { weeks } \\
(n=16)\end{array}$ & $\begin{array}{l}\text { Healing } \\
\text { period } \geq 24 \\
\text { weeks } \\
(n=9)\end{array}$ & $p$-value & $\begin{array}{l}\text { Non-molar } \\
\text { area } \\
(n=9)\end{array}$ & $\begin{array}{l}\text { Molar area } \\
(\mathrm{n}=16)\end{array}$ & $p$-value & $\begin{array}{l}\text { Maxilla } \\
(\mathrm{n}=10)\end{array}$ & $\begin{array}{l}\text { Mandible } \\
(\mathrm{n}=15)\end{array}$ & $p$-value \\
\hline Age (years) & $61.81 \pm 9.02$ & $60.33 \pm 14.69$ & & $66.44 \pm 12.64$ & $58.38 \pm 9.33$ & & $63.60 \pm 11.99$ & $59.73 \pm 10.61$ & \\
\hline \multicolumn{10}{|l|}{ Sex } \\
\hline Female & $6(24 \%)$ & $3(12 \%)$ & & $5(20 \%)$ & $4(16 \%)$ & & $3(12 \%)$ & $6(24 \%)$ & \\
\hline \multicolumn{10}{|l|}{ Histomorphometric results } \\
\hline New bone $(\%)$ & $9.53 \pm 12.94$ & $11.44 \pm 7.74$ & .692 & $10.22 \pm 11.29$ & $10.21 \pm 11.52$ & 999 & $6.53 \pm 7.86$ & $12.68 \pm 12.62$ & .185 \\
\hline Residual graft (\%) & $13.84 \pm 8.81$ & $14.44 \pm 9.30$ & .875 & $15.19 \pm 9.62$ & $13.41 \pm 8.56$ & .638 & $13.31 \pm 10.09$ & $14.55 \pm 8.16$ & .736 \\
\hline
\end{tabular}

All data are presented as the mean \pm standard deviation or frequency with percentage. Demographic characteristics were compared using the t-test for continuous variables between the two groups. Statistical significance was set at $p<.05$

\section{Non-molar vs. molar}

From the second histomorphometric assessment, the proportions ( \pm SDs) of new bone, residual graft, and fibrovascular tissue were 10.22. $\pm 11.29 \%, 15.19 . \pm 9.62 \%$, and $74.58 . \pm 11.95 \%$ in the non-molar group and $10.21 \pm 11.52 \%, 13.41 \pm 8.56 \%$, and $76.38 \pm 11.95 \%$ in the molar group, respectively. There was no significant difference between the proportions of new bone $(p=.999)$, residual graft $(p=.638)$, and fibrovascular tissue $(p=.723)$ in the two groups.

\section{Maxilla vs. mandible}

From the third histomorphometric assessment, the proportions ( \pm SDs) of new bone, residual graft, and fibrovascular tissue were $6.53 \pm 7.86 \%, 13.31 \pm 10.09 \%$, and $80.16 \pm 12.74 \%$ in the maxilla group and $12.68 \pm 12.62 \%, 14.55 \pm 8.16 \%$, and $72.77 \pm 10.41 \%$ in the mandible group, respectively. There was no significant difference between the proportions of new bone $(p=.185)$, residual graft $(p=.736)$, and fibrovascular tissue $(p=.125)$ in the two groups (Table 2).

\section{Discussion}

In this study, ridge preservation was performed using the DPBM. Ridge preservation sustains the width and height of the alveolar bone, and it is better to use it than to proceed with extraction alone. ${ }^{12}$ Lang et al. reported that 6 months after extraction the average width and height of the alveolar bone 
reduced by $3.8 \mathrm{~mm}$ and $1.24 \mathrm{~mm}$, respectively. ${ }^{13}$ Vignoletti et al. reported that ridge preservation sustains the soft and hard tissues, maintains the volume of alveolar bone, maintains technically and esthetically optimal conditions, and simplifies the treatment process. ${ }^{14}$ Various materials, such as bovine bone mineral, have been used for ridge preservation. Bovine bones are similar to human bones, and they satisfy several ideal conditions, such as they can withstand changes in the body with a slow substitution rate, which makes it possible to maintain a good space for an extended period. ${ }^{15}$ A systematic review concluded that ridge preservation could reduce the risk of further bone augmentation in the future. ${ }^{16}$

A relatively low proportion of new bone was found than that reported in the previous studies; approximately $30 \%$ of new histological bone formation after ridge preservation techniques has been reported. ${ }^{17-20}$ However, compared to the previous studies on alveolar ridge preservation of damaged extraction sockets using bovine or porcine bone mineral, the proportions ( \pm SDs) of new bone, residual graft, and fibrovascular tissue were $15.07 \pm 10.52 \%, 12.37 \pm 5.67 \%$, and $72.56 \pm 10.07 \%$ in the group using bovine bone and $18.47 \pm 11.47 \%, 12.21 \pm 5.75 \%$, and $69.32 \pm 10.02 \%$ in the group using porcine bone, respectively. ${ }^{21}$ The results of our study show a similar or slightly lower ratio compared to the previous study. Furthermore, the two studies share similarities with respect to the damaged extraction sockets. It can be expected that the extraction socket wall was damaged, and this affected the formation of new bone.

This retrospective study was conducted based on the following two perspectives. First, longer healing durations are associated with greater absorption of residual bone grafts, newer bone formation, and lower proportions of fibrous vascular tissue.

We set the threshold healing duration at 24 weeks. In previous studies, the healing duration spanned the completion of the procedure through the observation of the minimum volumetric change, and 4-6 months was selected. ${ }^{22,23}$ Accordingly, we intended to report changes in each component after 24 weeks, when the change in the alveolar ridge became minimal. According to a previous study, xenograft did not absorb well and showed 35\% residual bone grafting after 7 months. ${ }^{24}$ The proportion of the residual bone grafting material (average: $11.11 \pm 10.58 \%$ ) was less than that reported by the previous study. Additional research should be added to determine whether this affects the volume in further studies.

The second perspective is the formation of new bone and absorption of residual bone grafts. The rate of fibrovascular proliferation was expected to be higher in areas where the blood flow was stable. In addition, the molar area was expected to require a longer time for new bone formation because of its larger socket size; however, no significant difference between the two groups was observed. ${ }^{25}$ In addition, it was expected that the maxilla would show greater new bone formation and absorption of residual bone 
grafts and lower fibrovascular proliferation than the mandible; however, no significant difference between the two groups was observed in this study. ${ }^{26}$ There was no significant difference in trabeculation or new bone formation in the maxilla and mandible in another study. Although it was not statistically significant in immunohistochemistry, a slightly higher vascular neoplasticity in the mandible than in the maxilla was observed ${ }^{27}$ There may have been minimal differences between the vascular formation and trabeculation of the maxilla and mandible as well as the premolar and molar areas; however, these differences were insignificant.

Although DPBM is used in bone regeneration procedures, including ridge preservation, research comparing DPBM with bovine bone mineral remains lacking. Although it has been verified that porcine bone mineral is highly biocompatible and has good bone conduction, various forms of bone resorption may occur with its use. ${ }^{28,29}$

Recently, Barone et al. reported vertical and horizontal resorption of the alveolar bone of $1.6 \mathrm{~mm}$ and $0.3-1.1 \mathrm{~mm}$, respectively, in their study on ridge preservation using porcine bone mineral. ${ }^{30}$ Thalmair et al. reported a horizontal bone resorption of $0.8 \mathrm{~mm} .{ }^{31}$ Both the studies showed promising results.

This retrospective study did not consider several variables (quantification of the remaining wall, bone quality, type of membrane, and distribution of location, among others), and the outcomes were mainly based on histomorphometric evaluation. Although all implants placed in sites using the DPBM functioned well for up to 3 years, histomorphometric analysis is a part of the research on bone graft materials based on this limited result. Further research considering other factors, including the longterm survival of placed implants, is recommended.

\section{Conclusion}

Within the limitations of this retrospective study, there were differences in the results of the histomorphometric analysis related to the healing period and location; however, these results were insignificant. Further studies are needed to determine the clinical relevance of these outcomes.

\section{Acknowledgment}

The authors express their gratitude to Young Lee (Research Institute of Veterans Health Service Medical Center) for her statistical advice. 


\section{References}

1. Barone A, Orlando B, Cingano L, Marconcini S, Derchi G, Covani U. A randomized clinical trial to evaluate and compare implants placed in augmented versus non-augmented extraction sockets: 3-year results. J Periodontol 2012;83:836-46.

2. Misch C, Suzuki J. Tooth extraction, socket grafting, and barrier membrane bone regeneration. Contemporary implant dentistry: St Louis (MI): Mosby Elsevier; 2008, p. 870-901.

3. Araujo MG, Sukekava F, Wennstrom JL, Lindhe J. Ridge alterations following implant placement in fresh extraction sockets: an experimental study in the dog. J Clin Periodontol 2005;32:645-52.

4. Horváth A, Mardas N, Mezzomo LA, Needleman IG, Donos N. Alveolar ridge preservation. A systematic review. Clin Oral Investig 2013;17:341-63.

5. Chen ST, Jr TGW, Hammerle CHF. Immediate or early placement of implants following tooth extraction: review of biologic basis, clinical procedures, and outcomes. Int J Oral Maxillofac Implants 2004;19:12-25.

6. Hammerle CH, Araujo MG, Simion M, Osteology Consensus G. Evidence-based knowledge on the biology and treatment of extraction sockets. Clin Oral Implants Res 2012;23:80-2.

7. Tan WL, Wong TL, Wong MC, Lang NP. A systematic review of post-extractional alveolar hard and soft tissue dimensional changes in humans. Clin Oral Implants Res 2012;23:1-21.

8. Nair PR, Schug J. Observations on healing of human tooth extraction sockets implanted with bioabsorbable polylactic-polyglycolic acids (PLGA) copolymer rootreplicas: a clinical, radiographic, and histologic follow-up report of 8 cases. Oral Surg Oral Med Oral Pathol Oral Radiol Endod 2004;97:559-69.

9. Cardaropoli G, Araujo M, Hayacibara R, Sukekava F, Lindhe J. Healing of extraction sockets and surgically produced - augmented and non-augmented - defects in the alveolar ridge. An experimental study in the dog. J Clin Periodontol 2005;32:435-40.

10. Boix D, Weiss P, Gauthier O, Guicheux J, Bouler J-M, Pilet P, et al. Injectable bone substitute to preserve alveolar ridge resorption after tooth extraction: a study in dog. J Mater Sci Mater Med 2006; 17:1145-52.

11. Clavero J, Lundgren S. Ramus or chin grafts for maxillary sinus inlay and local onlay augmentation: comparison of donor site morbidity and complications. Clin Implant Dent Relat Res 2003;5:154-60.

12. Iasella JM, Greenwell H, Miller RL, Hill M, Drisko C, Bohra AA, et al. Ridge preservation with freeze-dried bone allograft and a collagen membrane compared to extraction alone for implant site development: a clinical and histologic study in humans. J Periodontol 2003;74:990-9.

13. Lang NP, Pun L, Lau KY, Li KY, Wong M. A systematic review on survival and success rates of implants placed immediately into fresh extraction sockets after at least 1 year. Clin Oral Implants Res 2012;23:39-66.

14. Vignoletti F, Matesanz P, Rodrigo D, Figuero E, Martin C, Sanz M. Surgical protocols for ridge preservation after tooth extraction. A systematic review. Clin Oral Implants Res 2012;23:22-38.

15. Darby I. Periodontal materials. Aust Dent J 2011;56:107-18.

16. Mardas N, Trullenque-Eriksson A, MacBeth N, Petrie A, Donos N. Does ridge preservation following tooth extraction improve implant treatment outcomes: a systematic review: Group 4: Therapeutic concepts \& methods. Clin Oral Implants Res 2015;26:180-201.

17. Cook DC, Mealey BL. Histologic comparison of healing following tooth extraction with ridge preservation using two different xenograft protocols. J Periodontol 2013;84:585-94. 
18. Gholami GA, Najafi B, Mashhadiabbas F, Goetz W, Najafi S. Clinical, histologic and histomorphometric evaluation of socket preservation using a synthetic nanocrystalline hydroxyapatite in comparison with a bovine xenograft: a randomized clinical trial. Clin Oral Implants Res 2012; 23:1198-204.

19. Hoang TN, Mealey BL. Histologic comparison of healing after ridge preservation using human demineralized bone matrix putty with one versus two different-sized bone particles. J Periodontol 2012;83:174-81.

20. Serrano Méndez CA, Lang NP, Caneva M, Ramírez Lemus G, Mora Solano G, Botticelli D. Comparison of allografts and xenografts used for alveolar ridge preservation. A clinical and histomorphometric RCT in humans. Clin Implant Dent Relat Res 2017;19:608-15.

21. Koo TH, Song YW, Cha JK, Jung UW, Kim CS, Lee JS. Histologic analysis following grafting of damaged extraction sockets using deproteinized bovine or porcine bone mineral: A randomized clinical trial. Clin Oral Implants Res 2020;31:93-102.

22. Iasella JM, Greenwell H, Miller RL, Hill M, Drisko C, Bohra AA, et al. Ridge preservation with freeze-dried bone allograft and a collagen membrane compared to extraction alone for implant site development: A clinical and histologic study in humans. J Periodontol 2003;74:990-9.

23. Leblebicioglu B, Salas M, Ort Y, Johnson A, Yildiz VO, Kim DG, et al. Determinants of alveolar ridge preservation differ by anatomic location. J Clin Periodontol 2013;40:387-95.

24. De Risi V, Clementini M, Vittorini G, Mannocci A, De Sanctis M. Alveolar ridge preservation techniques: a systematic review and meta-analysis of histological and histomorphometrical data. Clin Oral Implants Res 2015;26:50-68.

25. Verdugo F, Laksmana T, D’Addona A, Uribarri A. Facial cortical bone regeneration post-extraction in non-grafted sockets allows for early implant placement and long-term functional stability. Arch Oral Biol 2020;112:104678.

26. Turkyilmaz I, Sennerby L, McGlumphy EA, Tözüm TF. Biomechanical aspects of primary implant stability: a human cadaver study. Clin Implant Dent Relat Res 2009;11:113-9.

27. Perelman-Karmon M, Kozlovsky A, Lilov R, Artzi Z. Socket site preservation using bovine bone mineral with and without a bioresorbable collagen membrane. Int J Periodontics Restorative Dent 2012;32:458-65.

28. Nannmark U, Sennerby L. The bone tissue responses to prehydrated and collagenated corticocancellous porcine bone grafts: a study in rabbit maxillary defects. Clin Implant Dent Relat Res 2008;10:264-70.

29. Orsini G, Scarano A, Piattelli M, Piccirilli M, Caputi S, Piattelli A. Histologic and ultrastructural analysis of regenerated bone in maxillary sinus augmentation using a porcine bone-derived biomaterial. J Periodontol 2006;77:1984-90.

30. Barone A, Ricci M, Tonelli P, Santini S, Covani U. Tissue changes of extraction sockets in humans: a comparison of spontaneous healing vs. ridge preservation with secondary soft tissue healing. Clin Oral Implants Res 2013;24:1231-7.

31. Thalmair T, Fickl S, Schneider D, Hinze M, Wachtel H. Dimensional alterations of extraction sites after different alveolar ridge preservation techniques-a volumetric study. J Clin Periodontol 2013;40:721-7. 